\section{FACILITIES FOR BOTANICAL RESEARCH}

$T H E$ botanical student who has successfully passed his final examination at one of our universities or local colleges will naturally begin to consider to what use he can devote the knowledge of facts and methods which he has acquired. To many it is unfortunately necessary to turn at once to some employment which will bring in a substantial return. Teaching pays; research does not; so the latter is often out of the question. But the few to whom earning money is not an immediate necessity hardly realise the splendid possibilities which lie before them. Of these men of more or less independent means some, from pure inertness, may be content to move within the narrow circle of their own university; others, following the example of their predecessors, will start on the German pilgrimage and sit at the feet of one or other of those teachers whose names they have long venerated from a distance. The advantage of working under the direction of one of these masters is no doubt very great, but still Germany lies in the temperate zone; the flora approximates nearly to that of Great Britain, and the gardens and hot-houses are in no way superior to our own. It rarely enters into the calculations of a young graduate that a journey to the tropics is a possible alternative to the German pilgrimage ; yet a circular recently issued by Dr. Treub, the well-known Director of the Botanical Garden at Buitenzorg, in Java, shows us that a visit of six months to the island is well within the range of any man who has $200 l$. to spend upon it. It is true that this cxpense is decidedly greater than that of living for six months in a German University town, but the advantages are correspondingly greater. In the first place, a tropical vegetation offers ample opportunities for research, especially in the branches of morphology and anatomy : in proof of this it is sufficient to turn over the pages of the Annales du Fardin botanique de Buitenzorg, and note the valuable results there detailed, chiefly from the pen of Dr. Treub himself; secondly, the Government of the Dutch Indies has recently placed suitable buildings at the disposal of the Director, who finds that he now has accommodation in his laboratory for four foreign investigators to work simultaneously; again, in the person of Dr. Treub, who, it may be mentioned, is a proficient in the English language, there is constantly present at Buitenzorg one of the first investigators of our time. In his circular Dr. Treub combats the idea which most of us would probably entertain, that Buitenzorg, being in the tropics, is necessarily unhealthy : he states that, though he will not pretend that a stranger coming to stay for four or five months cannot possibly fall ill, still the chances of contracting disease during that time are not notably greater than if one stayed at home or travelled on the continent of Europc. He recommends the period between October and April as the best, both as regards health, comfort, and the vegetation. Here is an opportunity the like of which has perhaps never before been offered to students, and one which can best be embraced by those who have not yet assumed the yoke of regular cmployment.

These facilities for botanical research in a tropical climate, thus offered freely to strangers by the Dutch, naturally suggest to the English mind that with all our colonies we have at present little of a like nature to offer: we have in our gardens at Calcutta and Peradeniya as good chances of establishing laboratories for botanical research as the Dutch had at Buitenzorg. Prof. Haeckel's interesting account of his recent tour in Ceylon, and of his visit to Peradeniya, gives some idea of the scope there would be for a young botanist to carry on morphological and anatomical work In the sphere of thallophytic botany Mr. H. M. Ward has already shown that a lengthened stay in the tropics may lead to the attainment of very valuable results.
But without going so far afield as the tropics, and at a decidedly less cost than such a journey would entail, plenty of scope may be found for satisfying the desire to investigate. Thus at the well-known marine biological station at Naples, the tables which are habitually occupied by zoologists might well be applied for by botanists : the numerous botanical memoirs issued from this institution by continental observers show that the institute of Dr. Dohrn is well adapted for the investigation of marine algæ as well as of marine animals.

A second marine station, devoted more particularly to the study of botany, is that at Antibes, now in the possession of the French Government; it was formerly the private residence of $M$. Thuret, to whose researches, in conjunction with M. Bornet, we owe so much of our knowledge of the reproductive processes of marine alga. Being compelled, for the sake of his health, to pass the winter months in the south, M. Gustave Thuret chose the beautiful promontory of Antibes for his residence. He laid out the grounds surrounding his villa as a winter garden, collecting together many rare and beautiful plants; at the same time, while attending to the collection and correct identification of terrestrial forms, he availed himself of the opportunity presented by residence on the coast to apply himself with vigour to those researches on marine algæe with which his name will a!ways be connected. On his death in 1875 , Mdme. Henri Thuret, desiring that the valuable collections of her brother-in-law should not be dispersed, bought the property for a sum of 200,000 francs, and presented it to the nation, the State undertaking the expenses of its maintenance. M. Naudin was appointed as director of the new institution. It is understood that on suitable application being made, foreigners can obtain admission to the laboratories of the Villa Thuret, which offer exceptional opportunities for the study both of marine and terrestrial forms.

However great the advantage may be of visiting countries of a climate different from our own, it is far from being necessary for an English student to leave his own country in order to satisfy his desire for research: the methods in use in the botanical laboratory are now taught with precision in our Universities: any student who has passed his final examination in the first class should be in a position to conduct a research successfully, if he has in him the necessary mental qualities. To such a man the resources of the Royal Gardens at Kew are a real mine which shows no sign of exhaustion. Not only may an investigator obtain access to the unrivalled collections, both living and dry, of the Royal Gardens, but, since Kew is in constant communication with distant countries, materials for completing a research may often be obtained which could scarcely be accessible in any other way. Through the munificence of the late Mr. Jodrell, a well-appointed laboratory has been erected in the Gardens, with the cxpress object of encouraging research.

Lastly, it must be admitted that the poverty of our efforts in recent years to investigate the marine alge of our coasts is little short of a disgrace to us as a maritime nation. Even our commonest sea-weeds are so little understood that they would well repay a careful investigation. Work on the sea-coast must for the present depend upon individual enterprise; but we may hope that shortly, when the Marine Biological Association has a fixed abode, botanists may be found ready to make a proper use of the opportunities which they will then enjoy.

In view of the constantly increasing bulk of botanical publications, which may be taken as an index of a steady increase in activity of research, it may be thought that it is more difficult at the present day to strike out an original line than at earlier periods in the development of the science. But, against this great increase of our 
knowledge we must set the more systematic training to which students are subjected before they are expected to take an independent line; secondly, the new methods of treatment and new points of view which now succeed one another more rapidly than at any previous time; and, thirdly, the very greatly increased facilities for research on the spot in foreign countries. When it is remembered how many of our most prominent men started their careers as travellers, the importance of the third of the above considerations will be valued as it ought to be. Those who are best able to appreciate the position of anatomical and physiological botany would probably be the first to agree that the opportunities for research in these branches, either in foreign lands or at home, are, at the present moment, better than they have been at any former period in the history of the science. If the botanical students of the present day content themselves with devoting their time and energy to working out small and uninteresting details, it is their own poverty of imagination and want of enterprise that are to blame.

F. O. B.

\section{MOLECULAR DYNAMICS}

I HAVE placed the three titles above this article not because I intend to deal with more than the last, but because they all deal with the same matter, and show how much the author's attention was directed to the subject during his three months' sojourn in America. The audience at the Baltimore lectures consisted chiefly of American professors, and a few English men of science attended a larger or smaller number of the lectures.

Speculation was rife as to the probable character of the lectures, and there was a general feeling that vortex motion would be largely dealt with. This, however, was not so. The course of twenty lectures was confined to the wave theory of light, largely dealing with the difficulties of that theory. The published lectures are not printed, but "jelligraphed," as Sir William Thomson would say. The number of copies is extremely limited, and are of unique interest, being reproduced from the short-hand notes taken at the lectures. Every one who knows how suggestive Sir William's lectures are and how fertile his mind is in bringing illustrative digressions to bear on the topic in hand, will expect these verbatim notes to be a rare treasure. Nor will he be disappointed. Mr. Hathaway, the reporter, has the unusual combination of being an expert stenographist, a skilful mathematician, and a clear and distinct caligraphist. His notes contain numerous errors, such as are unavoidable in such an undertaking, but, viewed as a whole, his work is almost a marvel.

The lectures treated of three branches of the subject: (I) the propagation of a disturbance through an elastic medium ; $(2)$ the character of molecular vibration; and (3) the influence of molecules on the propagation of waves. Each lecture generally dealt with two of these branches, and between the two parts of the lecture Sir William went among his andience and had some conversation with them. It was ever his object to discard the professorial attitude and give his lectures the aspect of conferences. Discussion did not end in the lecture-room, and the three weeks at Baltimore were like one long conference guided by the master mind. It is not surprising that at the end of that time there was a genuine feeling of sadness at parting on the part of teacher and taught alike.

The part of the lectures dealing with the propagation of an elastic disturbance could not be expected to contain

I "On Molecules," the Presidential Address to Section A of the British Association, August, 188 4. by Sir William Thomson.

"The Wave Theory of Light," a Lecture delivered by Sir William Thomson at Philadelphia on Sept. 29 , 1884 , published in NATURE, vol. xxxi p. gI.

Hopkins University Octuber, Dynami much novelty, but it was treated in so novel a manner and from so purely a physical point of view, that it could not but be instructive. Many of the old supporters of the theory dealt with it purely from a mathematical point of view. They treated the problem as a mathematical exercise, and did not hesitate to make unwarranted assumptions to produce pretty formulas or simple solutions. Even such men as Weber (in his "Theory of Magnetism ") and Green (in his "Wave Theory") have been guilty of this practice. Sir William Thomson never made any but physical assumptions, and these were made for reasons given. Rather than make a meaningless mathematical assumption he would prefer to burden his formulas with undetermined quantities, and even, if unable to reach the final solution, would rejoice in the richness of the formulas, which showed a potentiality of overcoming many difficulties. He does not always commend Rankine's mathematics, but he says this for him at p. I85: "Rankine did a great deal to cure the mathematical disease of asphasia from which we suffered so long. Faraday did most. The old mathematicians used neither diagrams to help people to understand their work, nor words to express their ideas. It was formulas, and formulas alone. Faraday was a great reformer in that respect with his language of 'lines of force,' \&c. Rankine was splendid in his vigour and in the grandeur of his Greek derivations." This refers to Rankine's nomenclature of different kinds of moduluses and their reciprocals-e.g. plagiotatic, thlipsinomic, \&c.

The first lecture is a summary of what is to come, and is partly historical. The difficulties in the way of accepting the wave theory of light are clearly pointed out. These are four in number.

First Difficulty: Dispersion.-The difficulty is to explain how velocity of propagation depends on period of vibration. Two explanations have been offered, that of Cauchy and that of Helmholtz. He does not delay much with Cauchy, who ascribed it to heterogeneousness. He prefers Helmholtz, who ascribes it to a compound structure of material molecules, which gives them a natural period of vibration. The one explanation has relation to wave-length, the other to period of vibration. The latter, he thinks, falls in better with results of spectrum analysis, \&c. A great portion of the lectures is devoted to expanding the notion of Helmholtz. The space occupied by a molecule must be filled with a substance differing from the ether either in rigidity or in density, or both. Lord Rayleigh has taken in hand this question in his researches on blue sky, and it seems that a variation of density is the principal or only effective cause. With respect to the new (Helmholtz-Thomson) spring and shell molecule, he says, "It seems to me that there must be something in this, that this, as a symbol, is certainly not an hypothesis, but a certainty."

Second Difficulty: the Ether.-He makes short work of the difficulty of reconciling almost perfect rigidity with almost perfect mobility. It is merely a matter of time. You can make a tuning-fork of Burgundy pitch when the period is a small fraction of a second, but a bullet will pass clean through several inches of it in six months. The ether may be highly elastic for vibrations executed in the 100 or 1600 million millionth of a second, but highly mobile to bodies going through it at the rate of twenty miles a second.

Third Difficulty: Refraction and Reflection.-Theoretical equations agree qualitatively with facts, but there are serious discordances when we come to quantitative measurements. Especitlly is this the case in the completeness of extinction of the ray polarised by reflection.

Fourth Difficulty: Double Refraction.-It is found that when the medium is displaced during wave-propagation in a double refracting crystal, the return force must depend on the direction of vibration, not on the plane of distortion, as all elastic theories indicate. Rankine and 